Article

\title{
Temporal Evolution of Corn Mass Production Based on Agro-Meteorological Modelling Controlled by Satellite Optical and SAR Images
}

\author{
Frédéric Baup $^{1, *} \mathbb{C}$, Maël Ameline ${ }^{1,2} \oplus$, Rémy Fieuzal ${ }^{3}$, Frédéric Frappart ${ }^{4} \oplus$, Samuel Corgne ${ }^{5}$ \\ and Jean-François Berthoumieu ${ }^{2}$ \\ 1 CESBIO (Centre d'Etudes Spatiales de la Biosphère), University of Toulouse, 18 avenue Edouard Belin, \\ 31401 Toulouse, France \\ 2 Association Climatologique de Moyenne-Garonne et du Sud-ouest, Aérodrome d'Agen, \\ 47520 Le Passage, France \\ 3 Airbus-Defense \& Space; 31 Rue des Cosmonautes, 31400 Toulouse, France \\ 4 LEGOS (Laboratoire d'Etudes en Géophysique et Océanographie Spatiale), University of Toulouse, \\ 14 avenue Edouard Belin, 31400 Toulouse, France \\ 5 LETG (Littoral, Environnement, Télédétection et Géomatique), University of Rennes, 35000 Rennes, France \\ * Correspondence: frederic.baup@cesbio.cnes.fr; Tel.: +33-561-626-344
}

Received: 11 June 2019; Accepted: 2 August 2019; Published: 22 August 2019

\begin{abstract}
This work aims to provide daily estimates of the evolution of popcorn dry masses at the field scale using an agro-meteorological model, named the simple algorithm for yield model combined with a water balance model (SAFY-WB), controlled by the Green Area Index (GAI), derived from satellite images acquired in the microwave and optical domains. Synthetic aperture radar (SAR) satellite information $\left(\sigma^{\circ} \mathrm{VH} / \mathrm{VV}\right)$ was provided by the Sentinel-1A (S1-A) mission through two orbits (30 and 132), with a repetitiveness of six days. The optical data were obtained from the Landsat-8 mission. SAR and optical data were acquired over one complete agricultural season, in 2016, over a test site located in the southwest of France. The results show that the total dry masses of corn can be estimated accurately $\left(\mathrm{R}^{2}=0.92\right)$ at daily time steps due to a combination of satellite and model data. The SAR data are more suitable for characterizing the first period of crop development (until the end of flowering), whereas the optical data can be used throughout the crop cycle. Moreover, the model offers good performances in plant $\left(R^{2}=0.90\right)$ and ear $\left(R^{2}=0.93\right)$ mass retrieval, irrespective of the phenological stage. The results also reveal that four phenological stages (four to five leaves, flowering, ripening, and harvest) can be accurately predicted by the proposed approach $\left(R^{2}=0.98\right.$; root-mean-square error (RMSE) = seven days). Nevertheless, some important points must be taken into account before assimilation, namely the SAR signal must be corrected with respect to thermal noise before being assimilated, and the relationship estimated between the GAI and SAR signal must be performed over fields cultivated without intercrops. These results are unique in the literature and provide a new way to better monitor corn production over time.
\end{abstract}

Keywords: remote sensing; Sentinel-1; SAR; SAFY-WB; crop production; maize

\section{Introduction}

Identifying the effective management of agricultural land is essential in order to achieve high socio-economic performance while limiting environmental impacts and ensuring the sustainability of resources. Through these direct and indirect effects on many surface balances (carbon, nitrogen, water, or energy), crops appear as the central element of agro-systems, with their development testifying to the interactions between the edaphological and climatic conditions being closely dependent on 
cultural practices (tillage, fertilizer, irrigation, and residue management) [1-4]. The quantification of the advantages or disadvantages associated with the implemented cultural practices then involves the achievement of a balance sheet based on monitoring the cultures, by targeting the key integrative variables (e.g., leaf area index, biomass, and yield) [5-7]. In this context, the use of satellite imagery combined with a crop functioning model constitutes a useful tool for diagnosis at a landscape scale.

The recent launch of the Sentinel-1, Sentinel-2, and Landsat- 8 satellite missions has opened the way to new opportunities for the combined use of data acquired in visible, infrared, and microwave wavelengths [8-10]. In the past, the lack of near-synchronous acquisition of optical and synthetic aperture radar (SAR) image time series during the same agricultural season restricted the possibilities of joint signal analysis to a limited number of studies [11-13]. The majority of the studies were then based on a few images, with the analyses of the satellite signals being often temporally and/or spatially separated, which made a comparison of the sensitivity and dynamic observed for contrasting surface states difficult. Nevertheless, these studies provide interesting study cases of the possibilities of using these data in a context of monitoring agricultural areas, with various issues, ranging from land cover classification [14] to the monitoring of crop or soil parameters [15-17], the detection of specific cultural practices [18-20], or damage concerning crops [21].

Vegetation indices derived from optical image reflectance are often used for monitoring the photosynthetic activity of vegetation during the phenological cycle [22] or to estimate biophysical parameters such as the leaf area index (LAI) or the fraction of absorbed photosynthetically active radiation (FAPAR). Hence, the approaches aiming at modeling the crop cycle at a regional scale were primarily based on the assimilation of optical images [22-27] into a simple agro-meteorological model, such as GRAMI [28], Aquacrop [29], or the simple algorithm for yield model combined with a water balance model (SAFY-WB) [30,31].

The limits encountered by the use of optical reflectance/indices are inherent to the image specificities, with, for instance, saturation of the indices when the vegetation becomes dense, or with a lack of observation during cloudy periods. The synthetic aperture radar (SAR) data then constitute an alternative, providing information about substitution by targeting the same ([32,33]) or complementary $([16,34])$ variables as those derived from optical imagery. The combined use of optical and SAR images to constraint models remains original and stays confined to a limited number of studies; however, they have all demonstrated the interest of this kind of approach for improving crop monitoring [16,32,33,35,36]. Moreover, to the best of our knowledge, the monitoring of the popcorn variety has never been performed using satellite radar data in order to estimate the time courses of its masses and phenological stages.

In this context, the objective of this study is to estimate the evolution of popcorn dry masses at a field scale, as well as the daily temporal resolution using an agro-meteorological model (SAFY-WB) controlled by the Green Area Index (GAI) derived from satellite optical and SAR images. The remainder of this paper is structured as follows: the materials (site description, satellite and ground data, and model) and method are first presented (Section 2). Section 3 presents the results on mass simulations performed by the model controlled by GAI, derived from satellite data (combined use of SAR and optical images), followed by a discussion in Section 4 . The discussion evaluates the capacity of inferring corn phenological stages throughout the crop cycle, as well as their associated masses (ear, plant, and total masses). Moreover, the impact of (1) the SAR signal processing (speckle filtering and thermal noise removal), and (2) the intercrops' influences on SAR signal and masses retrieval are discussed.

\section{Materials and Method}

\subsection{Site Description}

The studied area is located in the southwest of France (Figure 1), near the city of Toulouse, in the Occitanie region $\left(43.49^{\circ} \mathrm{N} 0.93^{\circ} \mathrm{E}\right)$. This area is characterized by a temperate climate. It is highly anthropized, and mainly comprises seasonal crops, grasslands, forests, and urban areas. Among the 
different crop species, this work focused on eight corn fields dedicated to popcorn production. The areas of the corn fields ranged from 2.6 to 30.6 ha (13.8 ha on average).

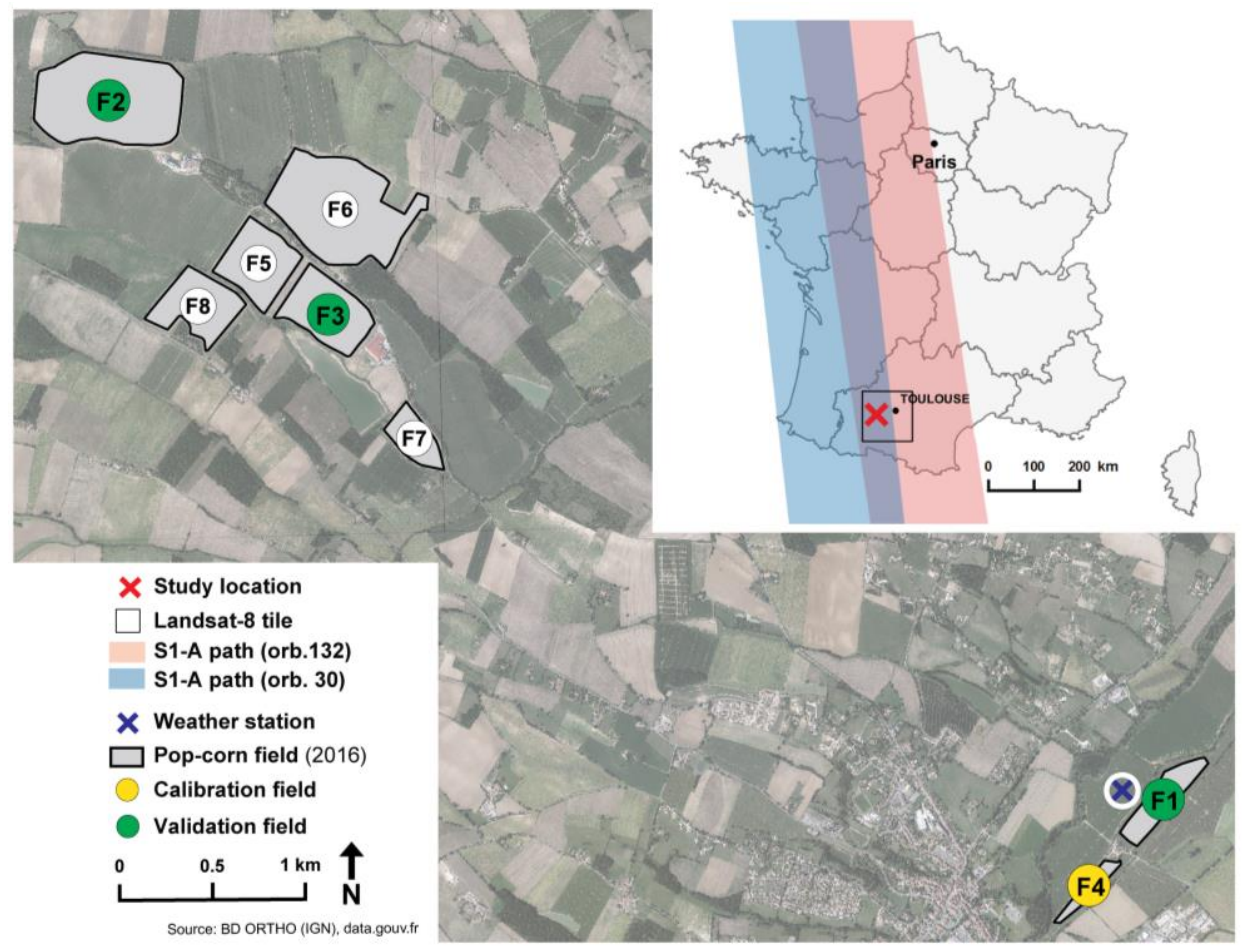

Figure 1. Location of the studied fields of popcorn, together with the swathes of Sentinel 1 (S1-A; orbits 132 and 30) and Landsat-8. The fields used for calibration (F4) and validation (F1, F2, and F3) are represented by yellow and green circles, respectively. Fields F5 to F8 belong to the same working farm and are used to study the spatial distribution of the production at a working-farm scale. The weather station is shown by the blue cross.

\subsection{Satellite and Ground Data}

\subsubsection{Satellite Data}

\section{Acquisition Calendar}

Satellite data were acquired throughout a seasonal crop period, from March to October 2016. The SAR data (51 images from orbit 30 (25) and 132 (26)) were acquired at C-band (at VV and VH polarizations) by the Sentinel 1A (S1-A) platform (freely available at Hub https://scihub.copernicus.eu/), whereas, the 18 optical data were acquired by Landsat- 8 Operational Land Imager (OLI) sensor (Figure 2).

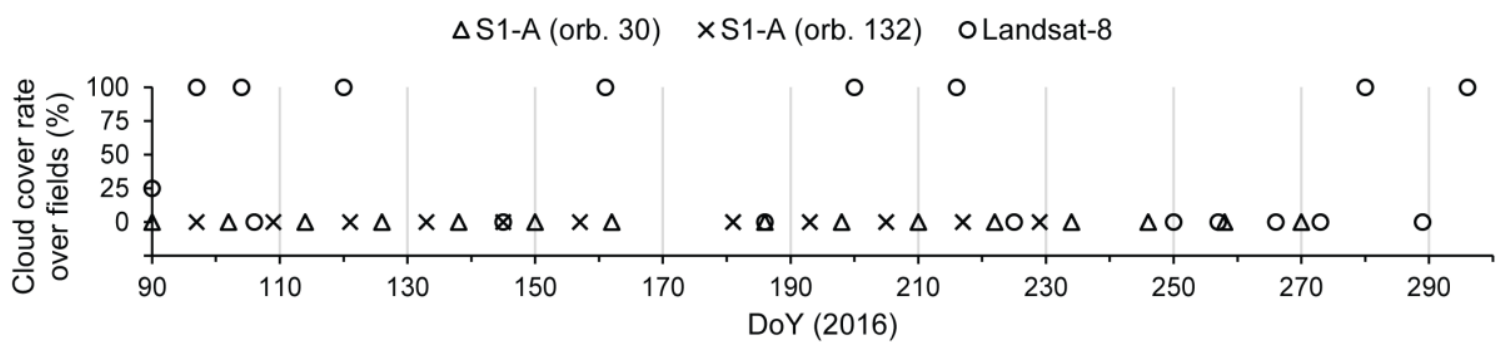

Figure 2. Time course of optical (Landsat-8 OLI) and synthetic aperture radar (SAR; orbit 30 and 132) acquisition during the cultivation cycle of popcorn (April to October) in 2016. The cloud cover rate over the fields is mentioned for the optical data (black circle). 


\section{Data Pre-Processing}

The SAR images were processed in ground range-detected (GRD) mode, with an incidence angle ranging from $29.1^{\circ}$ to $46.0^{\circ}$ [10]. The S1-A images were pre-processed (radiometric calibration, thermal noise, range doppler terrain correction, and re-sampled at $10 \times 10 \mathrm{~m}^{2}$ spacing) from the Google Earth engine website, so as to obtain the sigma-naught ratio $\left(\sigma_{\mathrm{VH} / \mathrm{VV}}^{0}\right)$, the best index for monitoring the vegetative part of corn, from the Sentinel-1 data [35,37].

Optical images were acquired by the sensor OLI onboard of Landsat 8 in four narrow spectral bands, ranging from 0.45 to $0.89 \mu \mathrm{m}$, which correspond to the blue, green, red, and near-infrared domains. They were processed using the level 2A processor, named "multi-sensor atmospheric correction and cloud screening" (MACCS), and are available free of charge from Theia Land Data Services (https://www.theia-land.fr/en/). After preprocessing, only 10 images could be used over the fields (between days 90 and 290), because of cloud cover (mean temporal repetitiveness of 21 days instead of 16 in the nominal value). In the following, these images were used to derive the GAI.

\subsubsection{Ground Data}

Ground data were collected over four fields (identified as ID F1, F2, F3, and F4 in Figure 1). They concerned agricultural practices (e.g., irrigation, sowing, tillage, and harvesting) and vegetation parameters (crop height, main phenological stages, biomass, dry matter, and water content). The surface soil roughness was considered stable during the time after sowing because no tillage events occurred until harvest. Therefore, it was assumed that surface soil roughness changes had no significant impact on the optical and SAR signals. Fields F5 to F8 were used to study the spatial distribution of the production at the working farm scale in Section 3.3 (no ground data were available for these fields). F1 and F4 belong to one working farm, and the others belong to the second working farm.

These fields were sown during March and April and were harvested at the end of September and in early October 2016, as indicated in Table 1. Throughout the crop season, at least six vegetation measurements were performed for each field. Each measurement was composed of five plants of corn, from which the above-ground biomass was directly weighed in situ. Then, the total aboveground dry mass (TDM) was measured after crop drying (the samples were put in an oven for $48 \mathrm{~h}$ at $65^{\circ} \mathrm{C}$ ). The water content was finally derived from the difference between the total biomass and TDM. For these measurements, the ears and the rest of the plant (leaves and stems) were separated, giving access to the ear dry mass (EDM) and the plant dry mass (PDM), respectively.

Table 1. Dates of the sowing, harvest, and vegetation measurements of the four studied fields. The temporal reference is given in day of year (doy) for 2016, and also in ${ }^{\circ} \mathrm{C}$ day, according to an agronomic point of view.

\begin{tabular}{ccccc}
\hline Field ID & $\begin{array}{c}\text { Date of } \\
\text { Sowing }\end{array}$ & $\begin{array}{c}\text { Date of Harvest } \\
\text { (doy/ }{ }^{\circ} \text { C day) }\end{array}$ & $\begin{array}{c}\text { Number of } \\
\text { Samples }\end{array}$ & Date of Sampling (doy/ ${ }^{\circ} \mathbf{C}$ day) \\
\hline F1 & 102 & $278 / 2453$ & 7 & $\begin{array}{c}(133 / 214,148 / 352,169 / 599,195 / 985 \\
215 / 1299,232 / 1574,266 / 2095) \\
(133 / 201,169 / 586,195 / 971,215 / 1285 \\
232 / 1561,266 / 2081)\end{array}$ \\
F2 & 104 & $281 / 2264$ & 6 & $\begin{array}{c}(133 / 292,169 / 677,195 / 1063 \\
215 / 1377,232 / 1652,266 / 2173)\end{array}$ \\
F3 & 87 & $273 / 2261$ & 6 & $\begin{array}{c}(133 / 214,148 / 352,169 / 599,195 / 985 \\
215 / 1299,232 / 1574,266 / 2095)\end{array}$ \\
F4 & 102 & $278 / 2453$ & 7 &
\end{tabular}

Figure 3 presents an example of temporal dynamics of the dry masses (TDM, EDM, and PDM), crop water content, and phenological stages from the in-situ data processed for field F3 (Figure 1). The TDM starts increasing from emergence, to reach its maximum $\left(17.97 \mathrm{t} \cdot \mathrm{ha}^{-1}\right)$ just before harvest. The allocation of the mass to the ear starts from about $1000{ }^{\circ} \mathrm{C}$ day, and its dry mass reaches about $12 \mathrm{t} \cdot \mathrm{ha}^{-1}$ a few days before measurement. The water content, strongly correlated with the biomass 
$\left(\mathrm{R}^{2}\right.$ mean $=0.95$, not shown here), starts from $94 \%$ at emergence, and then decreases significantly from flowering, to reach about $25 \%$ at harvest ( $41 \%$ was measured a few days before harvest, whereas vegetation continued to strongly dry). Considering the measurements, the mass of the grain represents an average of $77 \%$ of the EDM at harvest day. The maximum height of this variety of corn ranged from 1.60 to $1.80 \mathrm{~m}$, depending on the studied field.

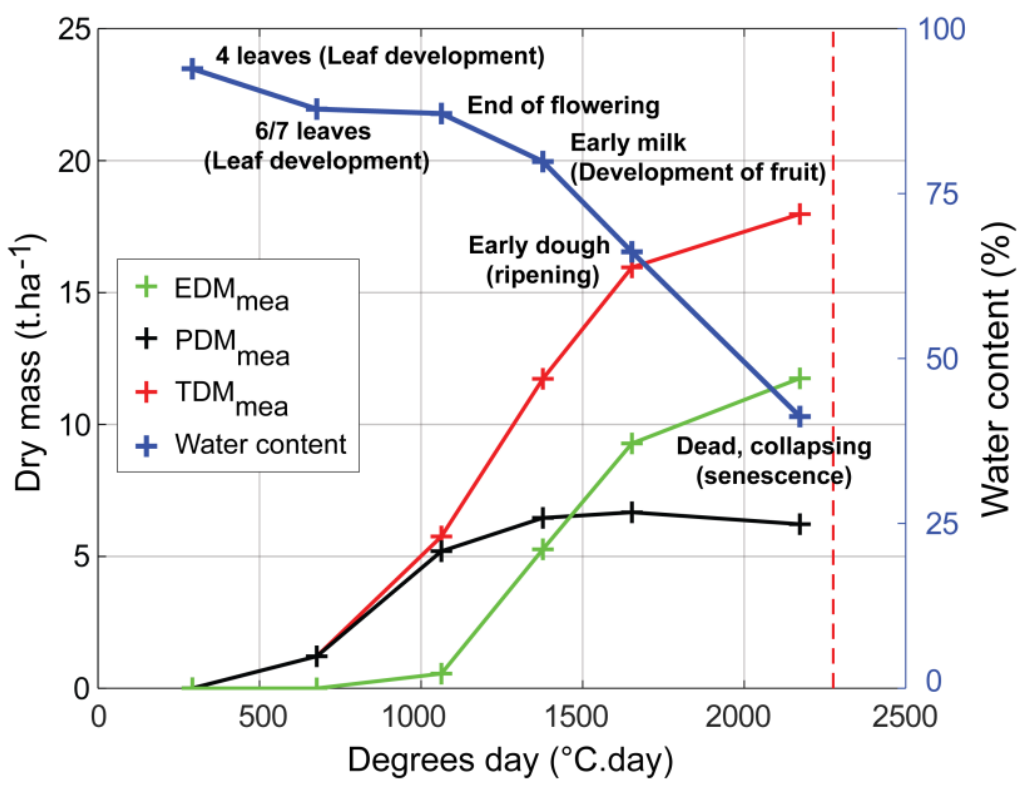

Figure 3. Temporal evolution of the crop water content (in blue), total dry masses of the corn (TDM; in red), divided into the following two components: ear dry mass (EDM; in green) and plant dry mass (PDM; in black). These measurements are performed for field F3. The vertical dashed red line represents the harvest date.

The meteorological data (i.e., air temperature, solar radiation, relative humidity, wind speed, and rainfall) were registered at semi-hourly time steps by one weather station (Figure 1). They were used to derive the daily reference evapotranspiration $\left(\mathrm{ET}_{0}\right)$ according to the FAO (Food and Agriculture Organization) method, and were used as the input variables of the agro-meteorological model (Figure 4).

\subsection{The Agro-Meteorological Model}

The agro-meteorological model, named SAFY-WB (simple algorithm for yield estimates coupled with a water balance model), was used to simulate the time courses (with a daily time step) of the popcorn masses (total, plant, and ear masses), GAI, and evapotranspiration. The model, detailed in the literature [30,31], requires the following meteorological input variables: the global solar radiation, air temperature, precipitation, and potential evapotranspiration (Figure 4). Only the main processes of the vegetation growth model are presented hereinafter.

The TDM and GAI are proportional to the absorbed photosynthetically active radiation, according to the effective light use efficiency, and a stress coefficient related to the meteorological conditions (relationship adapted from the literature [38], in Equations (1)-(4)):

$$
\begin{gathered}
T D M_{d o y}=T D M_{d o y-1}+\Delta T D M_{d o y} \\
\text { with, } \Delta T D M_{d o y}=E L U E \times P A R_{d o y} \times S c, \\
G A I_{d o y}=G A I_{d o y-1}+\Delta G A I_{d o y}, \\
\text { with, } \Delta G A I_{d o y}=\Delta T D M \times S L A_{d o y} \times P L I_{d o y}
\end{gathered}
$$


where ELUE represents the effective light use efficiency, SLA the specific leaf area, PLI the partitioning to leaf index, $S c$ the stress coefficient of water and temperature, and doy the day of the year.

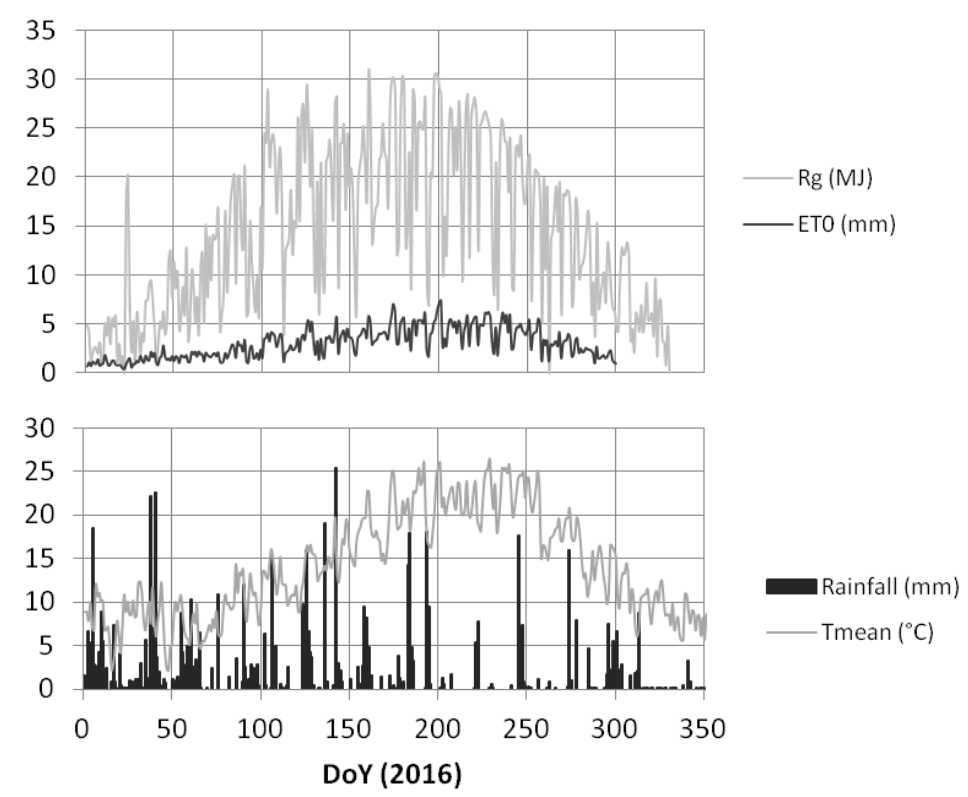

Figure 4. Temporal evolution of the climatic data used as the input of the agro-meteorological model ( $\mathrm{Rg}, \mathrm{ET}_{0}$, rainfall, and $\left.\mathrm{T}_{\text {mean }}\right)$.

The photosynthetically active fraction of solar radiation absorbed by the plants is proportional to GAI and $R g$, according to the Beer-Lambert law (Equation (5)):

$$
P A R_{\text {doy }}=0.47 \times R g \times\left(1-e^{\left(-0.6 \times G A I_{d o y}\right)}\right) .
$$

The leaf production and leaf senescence are controlled by a growing degree-day function. During the leaf growing period, a fraction of the daily DM production is allocated to the leaf production (LP) thanks to an empirical parameterization proposed by the authors of [39], in Equations (6) and (7):

$$
\begin{gathered}
P R T_{d o y}=\max \left(0, P l a \times e^{\left(P l b \times \sum \mathrm{Temp}_{\text {doy }}\right)}\right), \\
L P_{d o y}=\mathrm{TDM} \times P R T_{d o y} * \mathrm{SLA}_{\text {doy }},
\end{gathered}
$$

where, Pla and Plb (empirical parameters) drive the partitioning to the leaves.

The senescence occurred at a prescribed rate, when the air temperature accumulated from plant emergence $\left(\sum T e m p_{d o y}\right)$ reached a crop-specific threshold (given by its variety). A temperature-stress function affected the DM production, considering a 2-degree polynomial specified by an optimal value $\left(30^{\circ} \mathrm{C}\right)$ and two extreme values $\left(6\right.$ and $\left.42{ }^{\circ} \mathrm{C}\right)$, beyond which the corn growth stopped ([40]).

The formalism of this model is based on a limited number of parameters (six have been defined as target parameters through the sensitivity study described by the authors of [31]), which allow for combining the model with the remotely sensed data. Four of them describe the development stages of the crop, as follows: partitioning to the leaf parameters $\left(\mathrm{Pl}_{\mathrm{A}}\right.$ and $\left.\mathrm{Pl}_{\mathrm{B}}\right)$ is effective during the growth phase (Equations (6) and (7)), while the cumulative temperature, which induces senescence and the rate of senescence (Stt and Rs), is used to describe the last phenological stages. Parameter $D_{0}$ (corresponding to a few days after the emergence of corn) and the effective light use efficiency (ELUE) are related to agricultural practices (Equation (2)).

Four phenological stages are simulated by the model, as follows: four to five leaves, flowering, ripening, and harvest. They are derived from $\mathrm{D}_{0}$, from the day on which the EDM starts growing, when GAI starts decreasing, and when GAI reaches 0 , respectively. 
This type of approach has previously been validated for the monitoring of the crop cycle of wheat, corn, and sunflower, using only optical images [23,30,41], and for soybean, sunflower, and grain corn using both optical and SAR images [16,35,42].

\subsection{Methodology}

The methodology used to simulate the different masses from the model driven by satellite data is given in Figure 5.

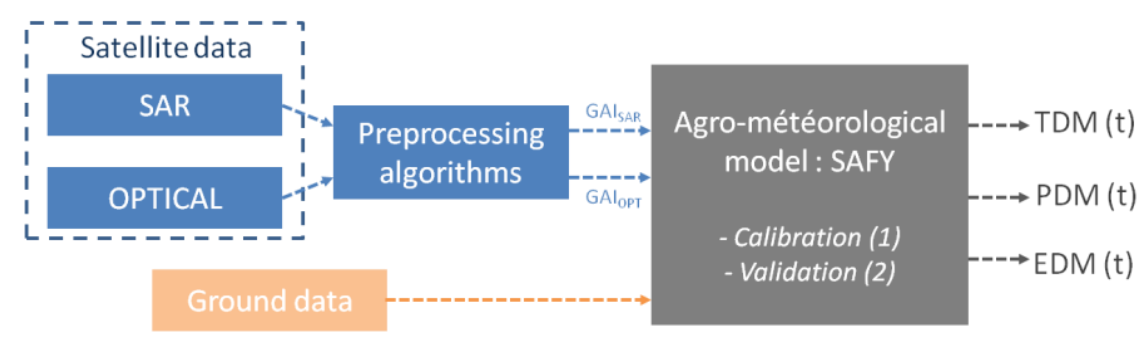

Figure 5. Methodology used to estimate TDM, PDM, and EDM from a combination of satellite images, the SAFY-WB model, and ground data.

The satellite data were first preprocessed following different steps according to their wavelength domain, as described in Section 2.2.1: Data Processing. The green area indices were then derived from both optical and radar images (GAI $\mathrm{Gpt}_{\mathrm{opt}}$ and $\left.\mathrm{GAI}_{\mathrm{SAR}}\right)$.

$\mathrm{GAI}_{\text {opt }}$ was generated through the BVNet tool (Biophysical Variables Neural NETwork), developed by the authors of [43]. This tool combines a radiative transfer model (SAIL + PROPSPECT $=$ PROSAIL) and artificial neural networks (ANNs). The radiative transfer model was first used to constitute a training dataset, with the constraint of estimating reflectance (from 400 to $2500 \mathrm{~nm}$ ) for a wide range of conditions regarding the crop biophysical variables. Artificial neural networks were then trained on the dataset estimated from PROSAIL (considering reflectance as the input variable, and GAI, FAPAR, and fCover as the output). Regarding GAI, the domain of validity of such an approach ranges between 0 and $6 \mathrm{~m}^{2} \cdot \mathrm{m}^{-2}$. The trained ANNs were finally applied to the satellite images, using green, red, and near-infrared reflectances. Such an approach has been validated in the South-West of France using optical images provided by Formosat-2, Spot-4, and Landsat-8, on independent ground measurements, showing an accurate performance with a correlation of 0.92 and a root mean square error (RMSE) of $0.4 \mathrm{~m}^{2} \cdot \mathrm{m}^{-2}$ for corn in the literature [41]. These good performances led us to use this approach to derive the GAI of popcorn from optical imagery.

$G A I_{S A R}$ are empirically derived from the sensitivity of the SAR signals to the GAI, from a non-linear regression (Equation (8)) valid from 0 to $1000{ }^{\circ} \mathrm{C}$ day. Among the tested SAR configurations $\left(\sigma^{\circ} \mathrm{VH}, \sigma^{\circ} \mathrm{VH} / \mathrm{VV}\right.$, and $\left.\sigma^{\circ} \mathrm{VV}\right)$, the best performances were obtained with $\sigma^{\circ} \mathrm{VH} / \mathrm{VV}\left(\mathrm{R}^{2}=0.97\right.$; RMSE $=$ $0.28 \mathrm{~m}^{2} \cdot \mathrm{m}^{-2}$ ). After a $1000{ }^{\circ} \mathrm{C}$ day, the quality of the relationship was strongly degraded, as $\sigma^{\circ} \mathrm{VH} / \mathrm{VV}$ saturated and remained at a high value until harvest, whereas the GAI decreased during senescence, as shown in the literature [35].

$$
G A I_{S A R}=52.92 \times e^{0.55 \times \sigma_{V H / V V}^{0}}
$$

Once generated, GAI $\mathrm{SAR}_{\mathrm{S}}$ and/or $\mathrm{GAI}_{\mathrm{opt}}$ were combined to the measured TDM (TDM mea $)$, in order to control the model during the steps of calibration and validation. This step aims at optimizing the target parameters inside their domains of variation to minimize the bi-objective cost function (Table 2) $[23,31,41]$.

The bi-objective cost function (Equation (11)) is based on the relative root mean square errors, considering the satellite derived green area index $\left(G A I_{\text {mea }}\right)$ and using the measured total dry mass dry as reference (Equations (9) and (10)): 


$$
\begin{gathered}
C_{G A I}=\sqrt{N_{G A I_{\text {mea }}}^{-1} \sum_{0<t_{i}<2500}\left[G A I_{\text {sim }}\left(t_{i}\right)-G A I_{\text {mea }}\left(t_{i}\right)\right]^{2}}, \\
C_{T D M}=\sqrt{N_{T D M_{\text {mea }}}^{-1} \sum_{0<t_{i}<2500}\left[T D M_{\text {sim }}\left(t_{i}\right)-T D M_{\text {mea }}\left(t_{i}\right)\right]^{2}}, \\
\bar{C}=\operatorname{sum}\left(\frac{{\overline{G A I_{\text {mea }}}}_{\text {TDM }_{\text {mea }}}-1}{1} \times C_{\text {GAI }} \times C_{T D M}\right),
\end{gathered}
$$

where $G A I_{\text {sim }}$ or $T D M_{\text {sim }}$ correspond to the values simulated by the model at time $\left(t_{i}\right), G A I_{m e a}$ and $T D M_{\text {mea }}$ are the values obtained from the measurements (satellite or ground), and $N$ represents the amount of data collected between sowing $\left(0^{\circ} \mathrm{C}\right.$ day $)$ and harvest $\left(2500^{\circ} \mathrm{C}\right.$ day $)$.

Table 2. Definition and domain of variation of the six target parameters, namely: the crop-specific parameters $\left(\mathrm{Pl}_{\mathrm{A}}, \mathrm{Pl}_{\mathrm{B}}, \mathrm{Stt}\right.$, and $\left.\mathrm{Rs}\right)$ and the field-specific parameters $\left(\mathrm{D}_{0}\right.$ and ELUE).

\begin{tabular}{cccc}
\hline Parameter & Definition & Domain of Variation & Unit \\
\hline $\mathrm{Pl}_{\mathrm{A}}$ & Partition-to-leaf function & $0.05-0.5$ & - \\
$\mathrm{Pl}_{\mathrm{B}}$ & Partition-to-leaf function & $10^{-5}-10^{-2}$ & - \\
$\mathrm{Stt}$ & Temperature sum for senescence & $0-2000$ & ${ }^{\circ} \mathrm{C}$ day \\
$\mathrm{Rs}$ & Rate of senescence & $0-10^{5}$ & ${ }^{\circ} \mathrm{C}$ \\
$\mathrm{D}_{0}$ & Day & $90-250$ & day \\
$\mathrm{ELUE}$ & Effective light-use efficiency & $0.5-6$ & g.MJ $^{-1}$ \\
\hline
\end{tabular}

In our case, the calibration/validation steps were performed from the data acquired from field F4 (Figure 1) and fields F1, F2, and F3, respectively. These steps consist of comparing the simulated TDM, PDM, and EDM to the measured values. Field F4 was chosen for calibration because it is flat, it is managed with conventional practices in contrast to others (tillage and no intercrop), and the culture is homogeneous. Hence, the results of the calibration were not affected by the local slope of the field, the heterogeneity of the culture, or the presence of an intercrop. The calibration step was performed for one field, reproducing how the agricultural decision-makers operate (they based their recommendations on the data collected in a field considered representative of an agricultural region).

As proposed by the authors of $[30,31]$, the four parameters describing the developmental stages of the crop were estimated during the calibration $\left(\mathrm{Pl}_{\mathrm{A}}, \mathrm{Pl}_{\mathrm{B}}, \mathrm{Stt}\right.$, and Rs) step and remained constant for the validation. Two parameters were optimized (using a simplex method) during the calibration and validation for each field, i.e., those related to the agricultural practices (namely, $\mathrm{D}_{0}$ and ELUE).

Finally, a production map was generated at a working farm scale (six fields, representing $101 \mathrm{ha}$ ), in order to analyze its spatial distribution, by considering three target simulation outputs, namely: total, ear, and plant masses.

\section{Results}

\subsection{Model Calibration}

Figure 6 presents the results of the calibration step and compares the temporal evolutions of the simulated and observed GAI and DM along the crop cycle, from sowing $\left(0^{\circ} \mathrm{C}\right.$ day $)$ to harvest (about $2500{ }^{\circ} \mathrm{C}$ day). The obtained values of the crop-specific parameters $\left(\mathrm{Pl}_{\mathrm{A}}, \mathrm{Pl}_{\mathrm{B}}, \mathrm{Stt}\right.$, and $\mathrm{Rs}$ ) and the field-specific parameters ( $\mathrm{D}_{0}$ and ELUE) are presented in Table 3.

The temporal trends of the GAI and DM (TDM, EDM, and PDM) were globally well reproduced. All of the biophysical variables were simulated with good performances, as demonstrated by the values of the determination coefficient, which were higher than 0.96 for the simulation of GAI, TDM, EDM, and TDM (Table 4). 


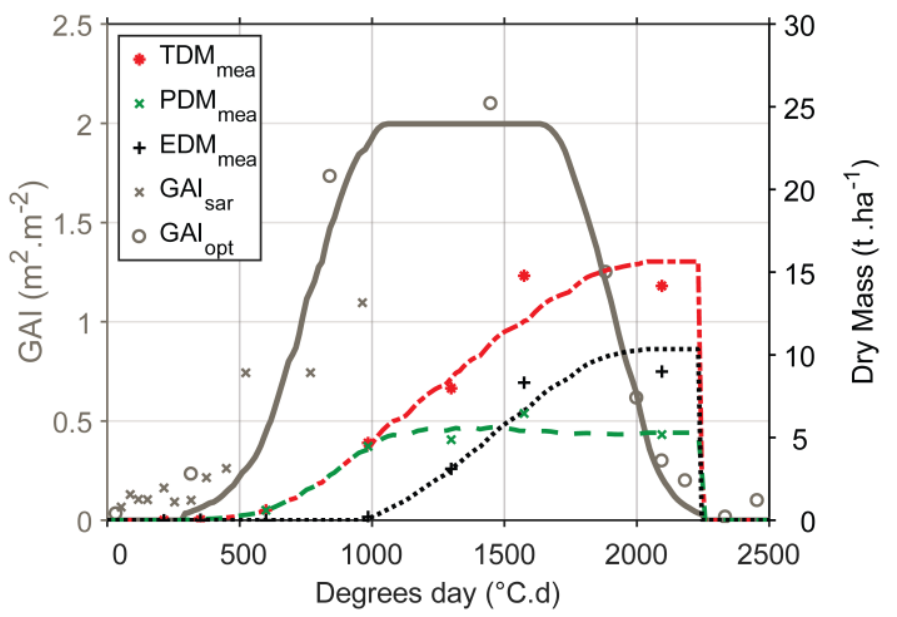

Figure 6. Comparisons between the simulated and measured masses for the calibration field (F4-Figure 1). The dry masses are divided into total, plant, and ear dry masses (TDM, PDM, and EDM). GAI $\mathrm{GAR}_{\mathrm{S}}$ and $\mathrm{GAI}_{\mathrm{opt}}$ are displayed by grey crosses or circles, respectively. Simulations of GAI, TDM, PDM, and EDM are represented by a continuous grey line, and dashed red, green, and black lines, respectively.

Table 3. Values of the crop-specific parameters $\left(\mathrm{Pl}_{\mathrm{A}}, \mathrm{Pl}_{\mathrm{B}}, \mathrm{Stt}\right.$, and $\left.\mathrm{Rs}\right)$ and the field-specific parameters $\left(\mathrm{D}_{0}\right.$ and ELUE) derived from the calibration step.

\begin{tabular}{cc}
\hline Parameter & Value \\
\hline $\mathrm{Pl}_{\mathrm{A}}$ & 0.08 \\
$\mathrm{Pl}_{\mathrm{B}}$ & $3.0 \times 10^{-3}$ \\
$\mathrm{Stt}$ & 1361 \\
$\mathrm{Rs}$ & 3569 \\
$\mathrm{D}_{0}$ & 142 \\
ELUE & 3.98 \\
\hline
\end{tabular}

Table 4. Statistical performances estimated for Green Area Index (GAI), Ear Dry Mass (EDM), Plant Dry Mass (PDM), and Total above ground Dry Mass (TDM) retrievals during the calibration step of the model.

\begin{tabular}{ccccccc}
\hline Target Output & $\mathbf{n}$ & $\mathbf{R}^{2}$ & $\mathbf{a}$ & $\mathbf{b}$ & RMSE & rRMSE (\%) \\
\hline GAI & 9 & 0.99 & 0.97 & -0.08 & 0.08 & 10.58 \\
EDM & 7 & 0.96 & 0.99 & -0.05 & 0.82 & 27.65 \\
PDM & 7 & 0.97 & 0.95 & 0.10 & 0.45 & 14.48 \\
TDM & 7 & 0.96 & 0.96 & 0.12 & 1.17 & 19.35 \\
\hline
\end{tabular}

Figure 6 also shows that the GAI, derived from optical or SAR reflectances, was quite stable and exhibited a similar pattern during the first phenological stages (between 0 and $500{ }^{\circ} \mathrm{C}$ day). It was not significantly affected by soil moisture change (as a result of irrigation and/or rainfall) when the surface was still mainly bare (just after sowing). This result confirms the pertinence of using the ratio of SAR backscattering coefficients $\left(\sigma^{\circ} \mathrm{VH} / \mathrm{VV}\right)$ instead of using simple co- or cross-polarization $\left(\sigma^{\circ} \mathrm{VV}\right.$ or $\left.\sigma^{\circ} \mathrm{VH}\right)$ to derive the GAI (the latter being much more affected by soil moisture changes, as demonstrated by the authors of [44]).

During the growing period (between 500 and $1000^{\circ} \mathrm{C}$ day), the GAI derived from the SAR or optical images exhibited a similar trend, but was not completely the same. This point has a limited impact on the simulation, as the agro-meteorological model was not able to produce so much vegetation variation during the growing period. This approach is thus robust enough to be not significantly affected by the difference in GAI retrieval until flowering $\left(1000^{\circ} \mathrm{C}\right.$ day), contrary to empirical approaches in which a small change in the backscattering coefficient induces a proportional change in the GAI 
retrieval [45-47]. From the end of flowering to the harvest, only GAI derived from optical data was assimilated, as the SAR signal saturated and was not sufficiently sensitive to senescence $[35,37,48,49]$.

\subsection{Model Validation-Mass Retrieval}

Figure 7 shows the comparison between the simulated masses (TDM, EDM, and PDM) and those measured in-situ (data used for calibration, displayed by black crosses in the figure, are not used to calculate the statistical performances of the model retrieval). The performances were good for the three parameters ( $\mathrm{R}^{2}>0.90$ and rRMSE $<30 \%$; Table 6 , with TNR). The results show that the model was able to simulate the masses over the full range of mass values (up to around $20 \mathrm{t} \cdot \mathrm{ha} \mathrm{a}^{-1}$ ). Nevertheless, the results show that the model was not able to reproduce the behavior of one specific point (surrounded in Figure $7 \mathrm{a}, \mathrm{c})$. This point was associated with lower in situ values than those for the simulated ones. This is explained by the falling of leaves, which occurred just before harvest (around $2100{ }^{\circ} \mathrm{C}$ day). This phenomenon, illustrated in Figure 8, was not simulated by the model. Consequently, the simulation overestimated the total dry mass.

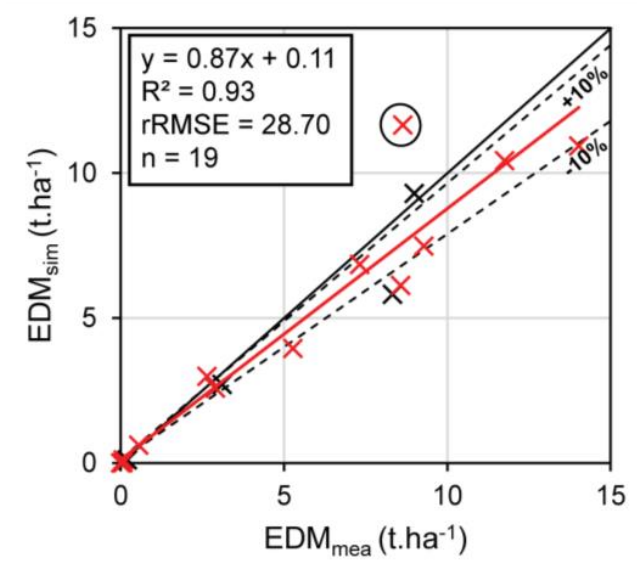

(a)

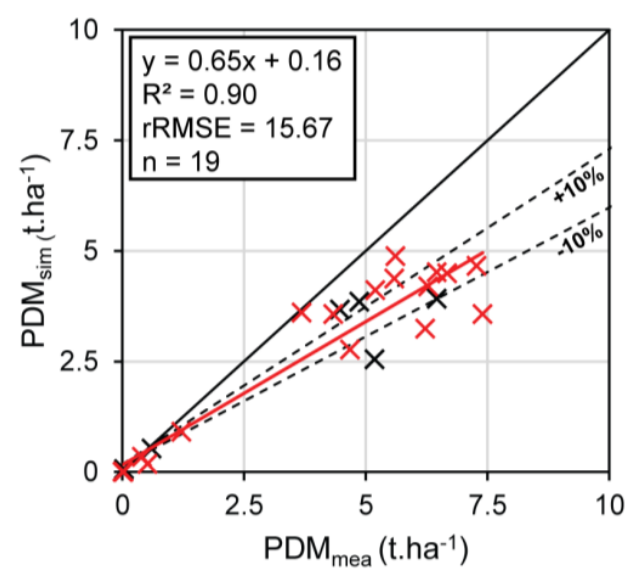

(b)

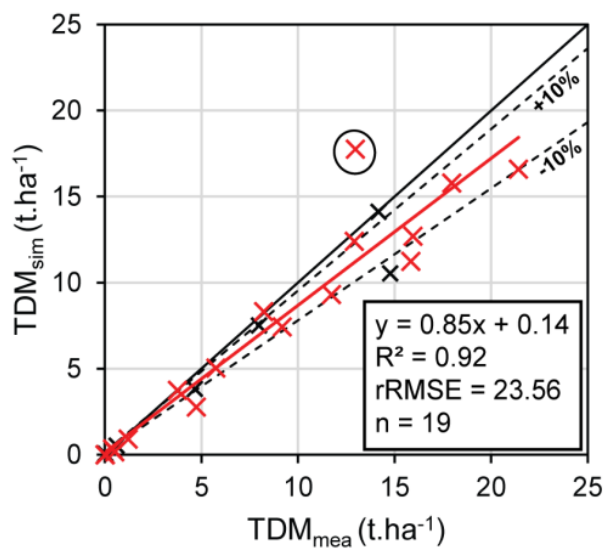

(c)

Figure 7. Comparisons between the measured and simulated dry masses of ear (EDM) (a), plant $(\mathrm{PDM})(\mathbf{b})$, and the total (TDM) (c). Black and red crosses represent the points used for calibration and validation, respectively. Only red crosses were used to calculate statistical performances. Black dashed lines represent a confidence interval of $\pm 10 \%$ around the trend line (red line).

The values of the field-specific parameters ( $\mathrm{D}_{0}$ and ELUE) are given in Table 5 for the eight studied fields (F1 to F8). The spread of $\mathrm{D}_{0}$ was in accordance with the different dates of sowing, whereas the values of ELUE (optimized around 4 g.MJ ${ }^{-1}$ ) were consistent with the literature [41]. 
Table 5. Values of the field-specific parameters ( $D_{0}$ and ELUE) derived from the validation step.

\begin{tabular}{ccccccccc}
\hline Parameter & F1 & F2 & F3 & F4 & F5 & F6 & F7 & F8 \\
\hline $\mathrm{D}_{0}($ DoY $)$ & 150 & 157 & 137 & 143 & 104 & 133 & 132 & 144 \\
ELUE $\left(\right.$ g.MJ $\left.^{-1}\right)$ & 4.32 & 4.40 & 3.93 & 3.79 & 3.14 & 3.67 & 3.73 & 4.12 \\
\hline
\end{tabular}

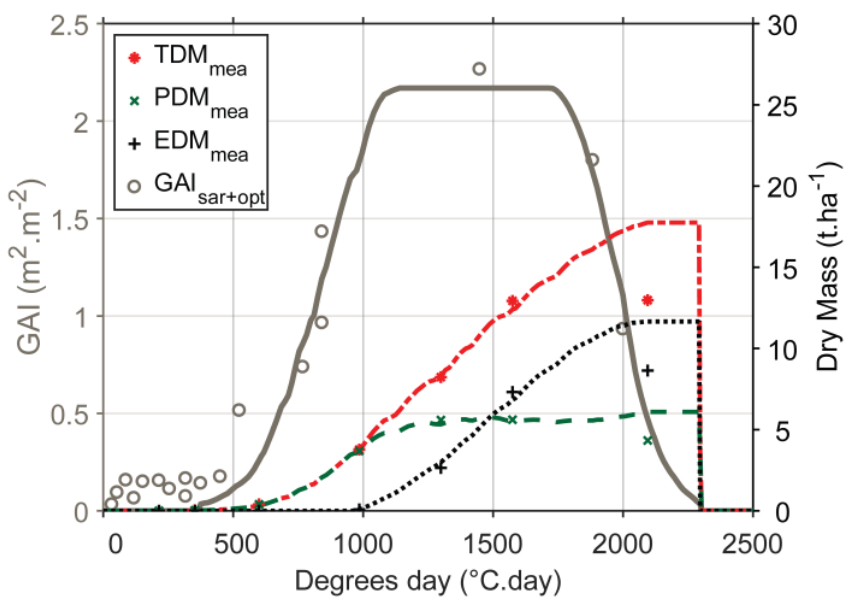

Figure 8. Comparisons between simulated and measured masses for the validation field (F1). Dry masses were divided into total, plant, and ear dry masses (TDM, PDM, and EDM, respectively). Simulations of the GAI, TDM, PDM, and EDM are represented by a continuous grey line, and dashed red, green, and black lines, respectively. The falling of leaves just before harvest is clearly visible in the last measurements, acquired around $2100{ }^{\circ} \mathrm{C}$ day.

\subsection{Mapping the Production of Corn over One Working Farm}

Once validated, the method was applied at a field scale for one working farm composed of six fields of corn (Figure 9). The approach allowed for the estimation of biomass production just after harvest (TDM, EDM, and PDM) for all of the considered fields. In our case, the total annual production ranged from 11.11 to $16.70 \mathrm{t} \cdot \mathrm{ha}^{-1}$. The results also show that the ear masses differed between the fields, ranging from $48 \mathrm{t}$ for the lower production (field F7) to $335 \mathrm{t}$ for the highest production (field F2). At the scale of the working farm, an amount of $1492 \mathrm{t}$ of corn was produced, distributed as $510 \mathrm{t}$ of plant and $982 \mathrm{t}$ of ears.

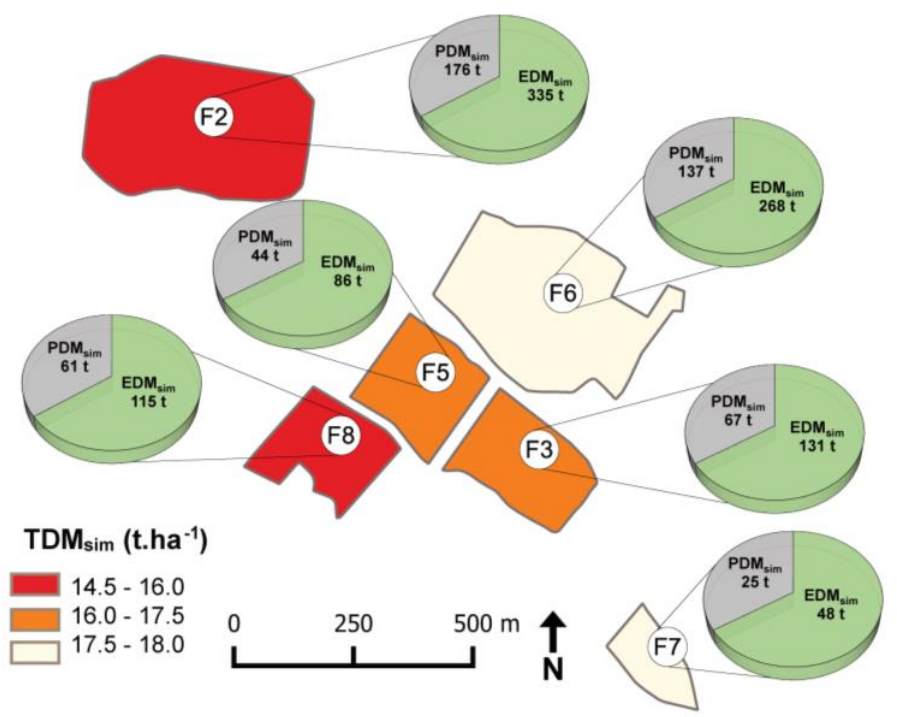

Figure 9. Map of corn masses simulated at harvest for a working farm. TDM, EDM, and PDM were provided from the simulation controlled by the SAR and optical satellite data. 


\section{Discussion}

\subsection{Can Corn Phenological Stages Be Accurately Inferred?}

Some of the main phenological stages were simulated by the model at different steps. The phenological stage "four to five leaves" was derived from the estimate of $D_{0}$, whereas the day of flowering was determined when the derivative of the function where PRT was equal to zero (Equation (6)). Ripening was given by $S_{t t}$, and the day of harvest was defined when the simulated GAI decreased to reach zero. These stages are very important in crop management, as they trigger nutrient uptake, e.g., nitrogen, phosphorus, potassium [50], and water consumption for grain production [51,52].

Following these assumptions, the model accurately reproduced the main phenological stages on average $\left(R^{2}=0.98\right.$ and RMSE = seven days on average; Figure 10). Nevertheless, the first stage (four to five leaves) was less accurate because of the difficulty in detecting the emergence of the crop from the satellite images acquired at a 10- or 20-m spatial resolution. During the first phenological stages, both the soil and vegetation contributed to the signal, and the small variation in the vegetation masses did not significantly affect the satellite signal at this spatial resolution $(>20 \mathrm{~m})$. Thus, it is very difficult to simulate the difference in crop development at the beginning of the growing period. Moreover, the dates of the phenological stages were estimated from the images taken on the day that the in-situ measurements were performed. In reality, the phenological stage covers a period of a few days around the date of observation. This phenomenon, not taken into account by the model, induces some offset between the day of the observed and simulated phenological stages.

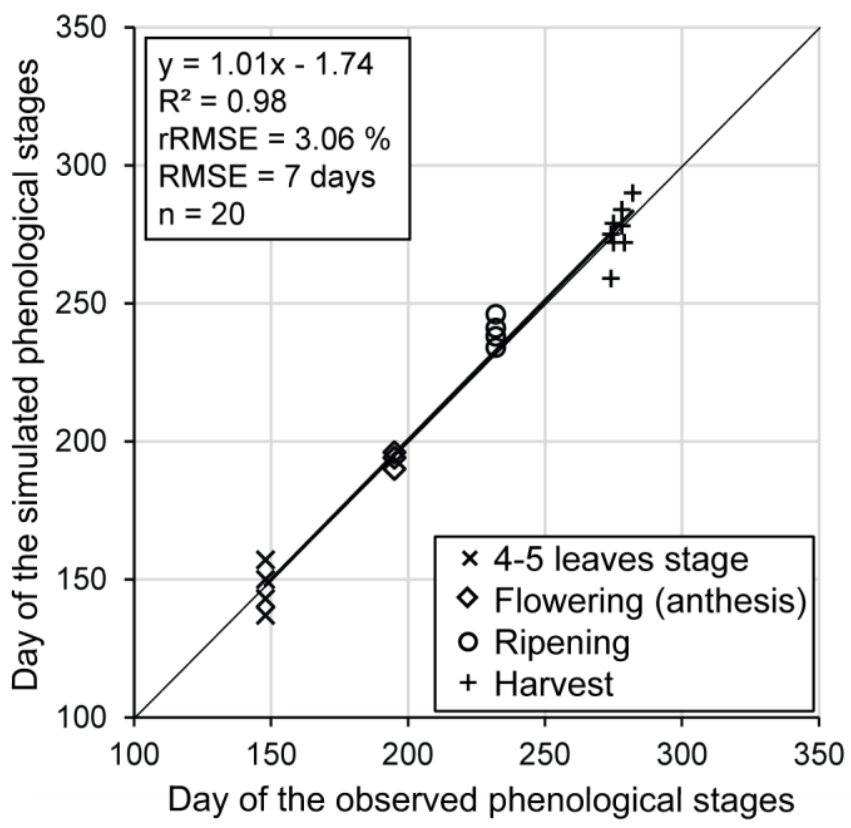

Figure 10. Comparison between the dates of the four simulated and observed phenological stages of corn (four to five leaves, flowering, ripening, and harvest).

Flowering and ripening were closely grouped in time and well detected, as they are mainly driven by the variety of the crop (taken into account in the model).

Finally, the date of harvest was always well reproduced. In the formalism of the model, the date of harvest was simulated when $\mathrm{GAI}_{\text {sim }}$ reverted to zero after ripening. The decrease of $\mathrm{GAI}_{\text {sim }} \mathrm{was}$ driven by a non-linear function governed by the GAI, assimilated during senescence and just after harvest. The date of harvest can be thus accurately estimated when the satellite data are numerous enough to control this non-linear function (this is our case). Nevertheless, the simulated date of harvest could have been less accurate if the satellite images were missing during this period. Given that the 
model was only controlled by optical data during this period, the quality of the results was strongly correlated with cloud cover. To overcome this limitation, the formalism of this process could be revised by using a threshold for grain humidity, for example, instead of using $\mathrm{GAI}_{\text {sim }}$. This threshold, defined as approximately $32-35 \%$, could be provided by seed-producers for each corn variety.

\subsection{Can Vegetation Mass Be Retrieved Irrespective the Phenologic Stage?}

As illustrated in Figure 7, the biomass can be accurately retrieved up to a couple of days before harvest. Nevertheless, in some particular cases, the model did not properly simulate the total masses just before harvest. These differences can be explained by the falling of the leaves of the corn during this period (phenomenon already observed for soybean in the literature [16]), which is not simulated by the model. Consequently, simulations strongly overestimated the total masses, particularly ear masses (Figure 7c), probably inducing an overestimation of the grain yield (not checked in our study because of the lack of yield data). To overcome this limitation, the falling of leaves should be implemented in the model by using a temperature function, for example, as this phenomenon cannot be observed on radar or optical signals [35,37]. This improvement will be useful for other crops whose leaves fall during certain phenological stages, e.g., grain maize, soybean, and rapeseed.

\subsection{What Is the Impact of the SAR Preprocessing Algorithm?}

The Sentinel-1 signal preprocessing algorithms differ from one institute to another, namely: openSarToolkit (FAO [53]), Google Earth Engine [54], S1tilling (available at http://tully.ups-tlse.fr/ koleckt/s1tiling, version of May 2019). The main preprocessing steps involved in this algorithm are illustrated in Figure 11.

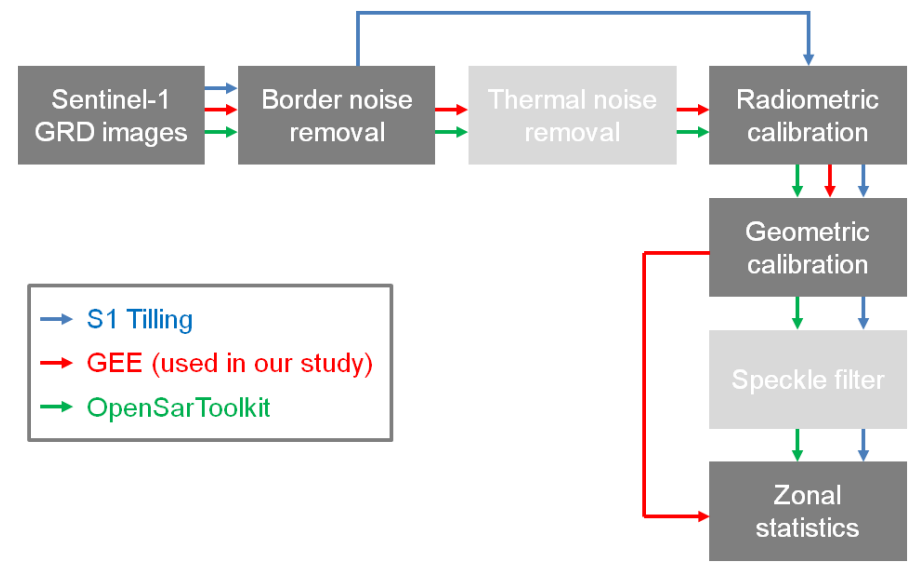

Figure 11. Main steps involved in the preprocessing radar signal, according to the algorithm used by FAO (OpenSar toolkit), Google (GEE; Google Earth Engine), and the French national space institute: CNES (S1-Tiling).

All of the algorithms integrate the steps of border noise removal [55], and radiometric and geometric correction [56]. The two main differences concern the application or not of thermal noise removal (TNR) and of the speckle filter [57]. The impacts of these two algorithms in terms of backscattering coefficients and biomass estimates are investigated in the two following subsections.

\subsubsection{Impact of the Speckle Filter on the Backscattering Coefficient at the Field Scale}

Figure 12 compares the $\sigma^{\circ} \mathrm{VH} / \mathrm{VV}$ (median value) extracted at a field scale along the crop growing season, over all the popcorn fields, with or without applying a $3 \times 3$ window adaptive Lee filter. With respect to the mean, the signals were strongly correlated with the $y=x$ regression line $\left(R^{2}=0.99\right)$. This result confirms that the application of a speckle filter has few impact on the SAR signal values extracted 
at the field scale, as this filter conserves the mean value inside a homogenous area [57]. Nevertheless, the backscattering ratio is not exactly the same because (1) the median values are displayed in Figure 12 (not the mean values), and (2) some fields have a too much of an elongated shape to apply the adaptive Lee filter properly. The only assumption of the filter is that the sample mean and variance of a pixel are equal to its local mean and variance, based on the pixels within a fixed neighborhood surrounding it [57]. When the studied fields have too much of an elongated shape (in the azimuth or range direction of the image), the neighborhood around one pixel is composed of a mixed-pixel (defined as a mixel). Contrary to pure pixels, mixels contain multiple constituents within a single pixel (corn, forest, bare soil, river, etc.), which can blur the value of backscattering coefficients to some extent.

These two combined effects-median instead of mean, and shape of the field-explain the slight scattering of the backscattering coefficients $(\mathrm{RMSE}=0.18 \mathrm{~dB}$ ) observed in Figure 12.

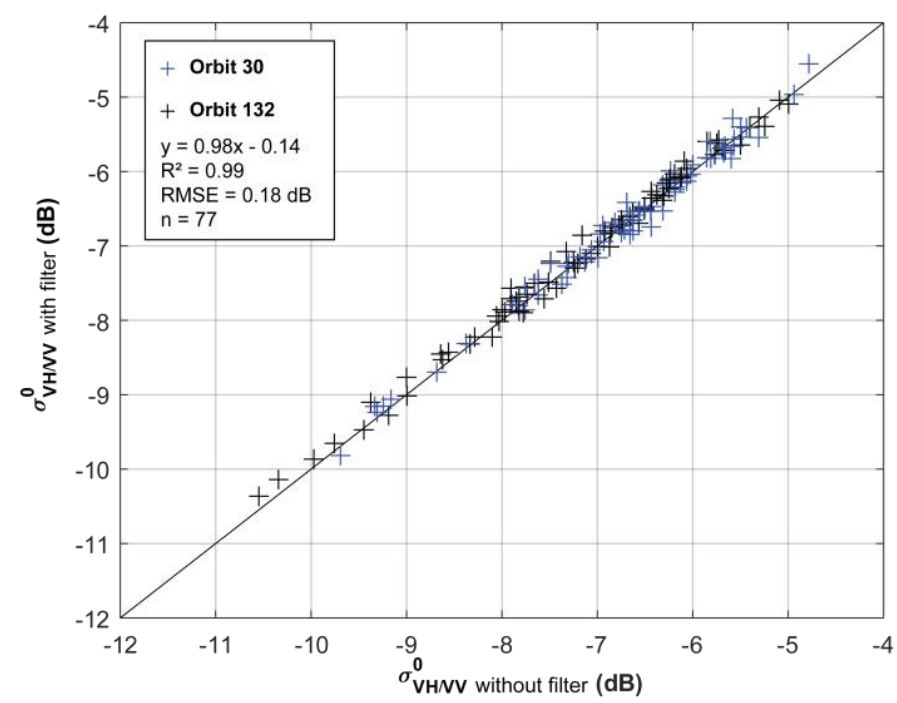

Figure 12. Comparison of the backscattering coefficient $\left(\sigma^{\circ} \mathrm{VH} / \mathrm{VV}\right)$ extracted at a field scale (between 0 and $1000^{\circ} \mathrm{C}$ day), with or without considering a $3 \times 3$ window adaptive Lee filter. Black and blue crosses represent the backscattering coefficients acquired in orbit 132 and 30, respectively.

Figure $13 b, d$,f presents the effects of the filter on the estimates of EDM, TDM, and PDM compared to the simulation performed using no filtered backscattering coefficients (at the date of the ground measurements). The relationships estimated between the masses could be considered quite similar for EDM, TDM, and PDM, except for some points surrounded by red ellipsoids.

These points correspond to the simulations performed in field F4, the more elongated field of the study, namely: $420 \mathrm{~m}$ long by $70 \mathrm{~m}$ wide on average (Figure 1). This size must be compared with the native spatial resolution of the SAR data, which is $20 \mathrm{~m}$ (in the range direction) by $22 \mathrm{~m}$ (in the azimuth direction). This means that a maximum of three pixels are pure along the range direction. For this field, the median backscattering coefficients $\left(\sigma^{\circ} \mathrm{VH} / \mathrm{VV}\right)$ were superior when the filter was applied. The overestimation of $\sigma^{\circ} \mathrm{VH} / \mathrm{VV}$ induced an overestimation of the associated $\mathrm{GAI}_{\mathrm{SAR}}$ and thus justified the higher simulations of the dry masses, as observed in Figure 13b,d,f. This phenomenon was not as pronounced on others fields, as they were larger and had a more regular rectangular shape.

\subsubsection{Impact of Thermal Noise Removal (TNR) on Backscattering Coefficients and on Mass Retrieval}

Figure 14 shows the influence of the thermal noise removal on the backscattering coefficient acquired at $\mathrm{VH}$ polarization, according to the acquisition orbit (30 or 132). The thermal noise comes from the electronic circuits and is one of the major sources of noise in microwaves. It mainly affects the signal when the signal to noise ratio (SNR) is low. Given that the cross-polarization signal is less powerful for corn than the co-polarization [35,37], this phenomenon mainly affects the cross 
polarization states. In the case of corn, the results of Figure 14 show that this correction can reach $2 \mathrm{~dB}$ in the worst case, when the VH decreases to $-24 \mathrm{~dB}$. Conversely, this correction is weak (less than $0.5 \mathrm{~dB}$ ) when the $\mathrm{HV}$ signal becomes greater than $-16 \mathrm{~dB}$.

(a)

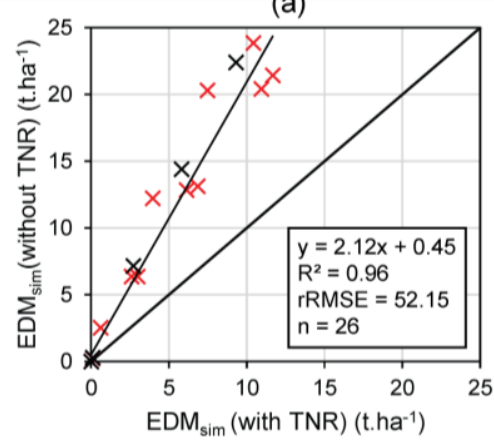

(c)

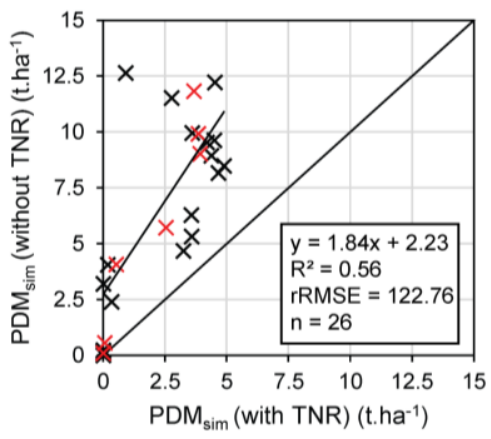

(e)

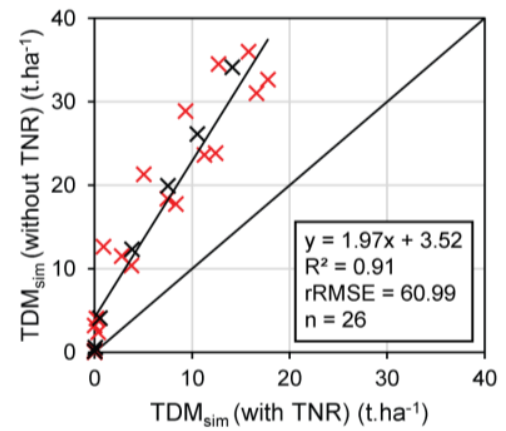

(b)

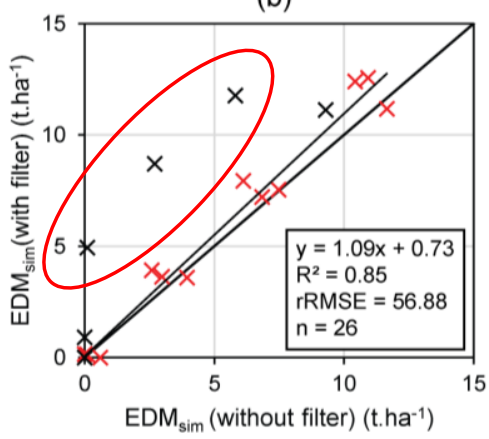

(d)

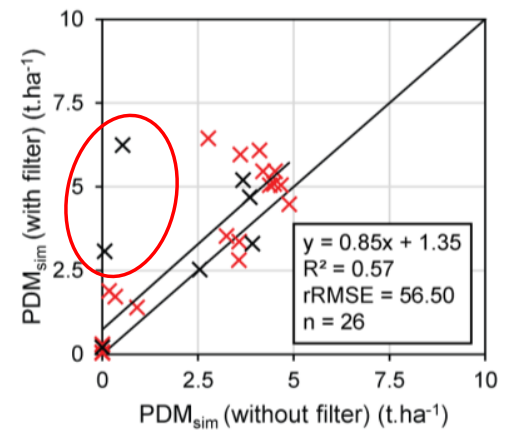

(f)

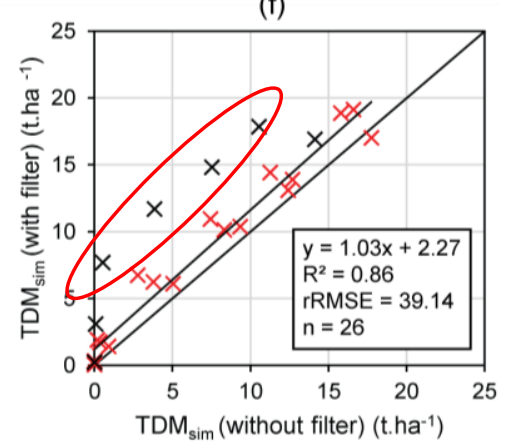

Figure 13. Comparison of simulated $\operatorname{EDM}(\mathbf{a}, \mathbf{b}), \operatorname{PDM}(\mathbf{c}, \mathbf{d}), \operatorname{TDM}(\mathbf{e}, \mathbf{f})$ with and without considering the thermal noise removal (left column) or the speckle filter (right column).

In VV polarization, there is no significant difference with or without the thermal noise removal, as the SNR is superior to the one obtained using VH signal (results not shown here).

The impact of the thermal noise on mass retrieval (EDM, PDM, and TDM) is illustrated in Figure 13a,c,e. In this figure, the masses simulated using the GAI $\mathrm{I}_{\mathrm{SAR}}$ derived from the backscattering signal corrected from the thermal noise (x-axes) are presented, versus those simulated without the thermal noise (y-axes). The results show that the performances for mass retrieval were strongly degraded when the TNR was not considered (Table 6). The relative errors exceeded 58\%, whereas they were lower than $30 \%$ when the radar signal was corrected for thermal noise. Moreover, the mean coefficients of determination decreased on average from 0.91 to 0.72 . This phenomenon can be explained by the fact that $\sigma^{\circ} \mathrm{VH}$ was overestimated when not corrected for thermal noise, especially when the signal was low, as illustrated in Figure 14. This phenomenon was particularly well marked during the first phenological stages of the crop, just after sowing, when soil was still bare and dry. The overestimation of $\sigma^{\circ} \mathrm{VH}$ directly impacted the value of $\mathrm{D}_{0}$ because the model wrongly considered that 
the vegetation started growing early in the season. Consequently, $\mathrm{D}_{0}$ decreased, and the duration of the crop cycle lengthened until harvest. This led to an overestimation of the simulated masses (EDM, PDM, and TDM) compared to the ground measurements.

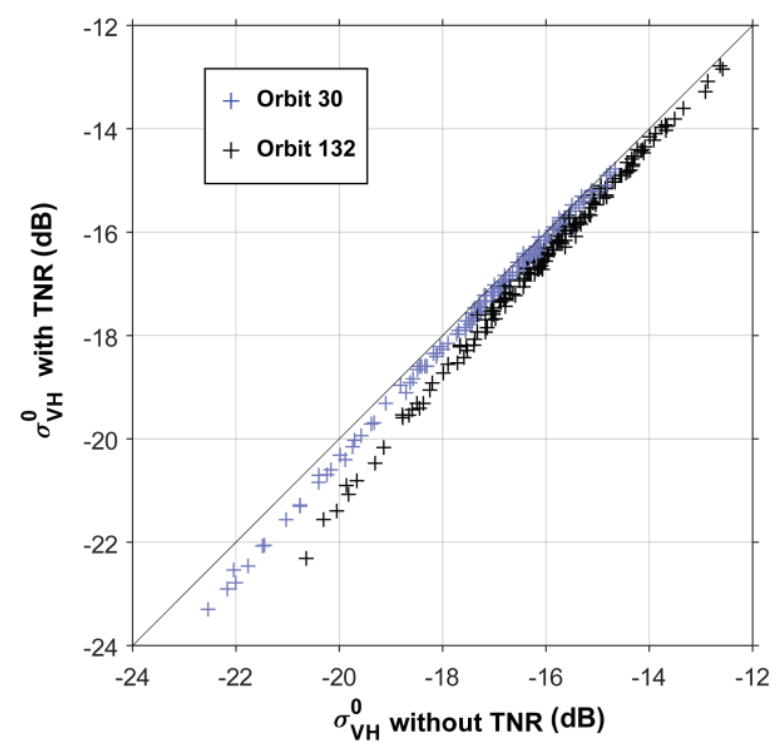

Figure 14. Comparison of backscattering coefficient extracted at a field scale (VH polarization), with or without considering the thermal noise correction. Black and blue crosses represent the backscattering coefficients acquired in orbit 132 and 30 , respectively.

Table 6. Statistical performances of the mass inversion (EDM, PDM, and TDM) with or without considering the thermal noise removal and speckle filter. TNR—-thermal noise removal.

\begin{tabular}{cccccccc}
\hline & & $\mathbf{n}$ & $\mathbf{R}^{2}$ & $\mathbf{a}$ & $\mathbf{b}$ & $\mathbf{R M S E}$ & rRMSE \\
\hline \multirow{3}{*}{ with TNR and without speckle filter } & EDM & 19 & 0.93 & 0.87 & 0.11 & 1.07 & 28.70 \\
& PDM & 19 & 0.90 & 0.65 & 0.16 & 0.59 & 15.67 \\
& TDM & 19 & 0.92 & 0.85 & 0.14 & 1.77 & 23.56 \\
\hline \multirow{3}{*}{ with TNR and with speckle filter } & EDM & 19 & 0.95 & 0.96 & 0.08 & 0.94 & 25.32 \\
& PDM & 19 & 0.68 & 0.65 & 0.92 & 1.23 & 32.74 \\
& TDM & 19 & 0.95 & 0.92 & 1.09 & 1.46 & 19.44 \\
\hline \multirow{2}{*}{ without TNR } & EDM & 19 & 0.94 & 1.81 & 0.57 & 2.19 & 58.57 \\
& PDM & 19 & 0.36 & 0.99 & 3.34 & 3.72 & 98.77 \\
& TDM & 19 & 0.87 & 1.65 & 4.02 & 4.46 & 59.40 \\
\hline
\end{tabular}

\subsection{What Is the Impact of an Intercrop?}

Intercrops play a major role in the quality of mass estimates. As illustrated in Figure 15, intercrops strongly affected the signal $\sigma_{V H / V V}^{0}$ at the beginning of the corn cycle (between 0 and $500{ }^{\circ} \mathrm{C}$ day). In our case, these crops were mainly composed of beans (Vicia faba L.). They were sown at the end of the year (before October-November) and were mechanically and chemically destroyed in May-June 2016, when corn began vegetative development. To restrain the impact of the SAR signal on the simulations, only $\sigma_{V H / V V}^{0}$ higher than $-7.5 \mathrm{~dB}$ was assimilated (level defined by the intersection of the black and green curves in Figure 15 at the bottom). The $\mathrm{GAI}_{\mathrm{opt}}$ estimated from the optical data was not affected by the presence of this crop, as it was undergoing senescence (Figure 15, at the top). At this stage, the color of the crop was close to the bare soil color (yellow, brown), and the BVnet algorithm (used to invert the $\mathrm{GAI}_{\mathrm{opt}}$ ) considered the reflectance to be the same as that observed for bare soil. Consequently, the algorithm simulated a GAI close to 0 . 
(a)

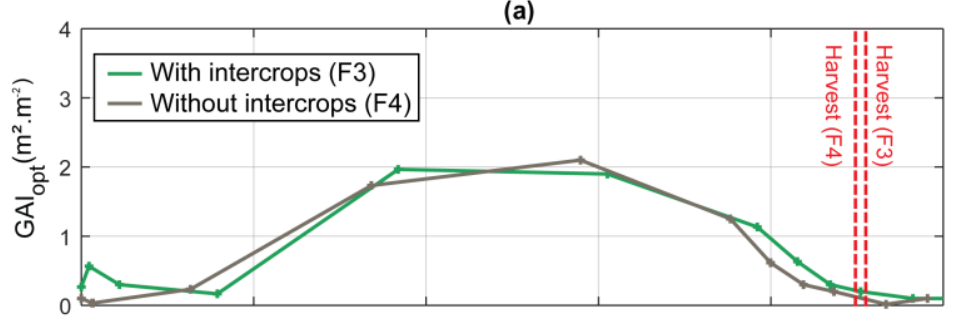

(b)

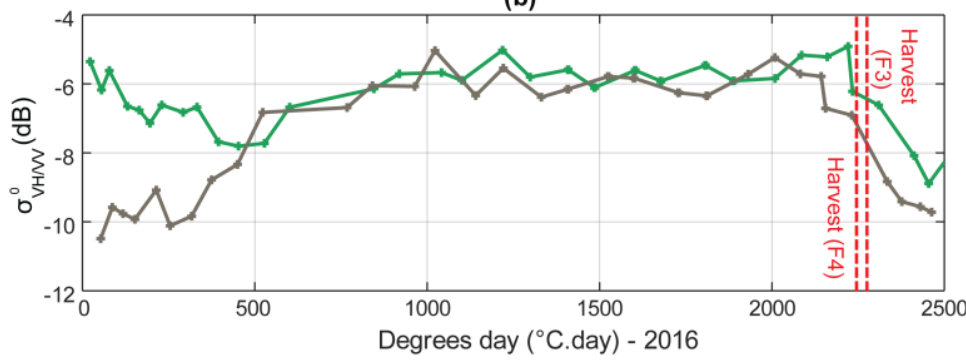

Figure 15. Temporal evolution of the $\mathrm{GAI}_{\mathrm{opt}}$ (a) and backscattering ratio $\sigma_{V H / V V}^{0}(\mathbf{b})$ according to the presence of intercrops (beans) inside the corn plot.

Without precaution, the impact of intercrops could affect the empirical function used to estimate the GAI from the SAR signals (Equation (8)). Figure 16 illustrates the impact of intercrops on the relationship estimated between GAI and $\sigma_{V H / V V}^{0}$. With intercrops, $\sigma_{V H / V V}^{0}$ strongly increased (until $-5 \mathrm{~dB}$ ), whereas the GAI of the corn remained low (less than $0.5 \mathrm{~m}^{2} \cdot \mathrm{m}^{-2}$ ). It is thus very important to remove a parcel with intercrops to estimate this relationship.

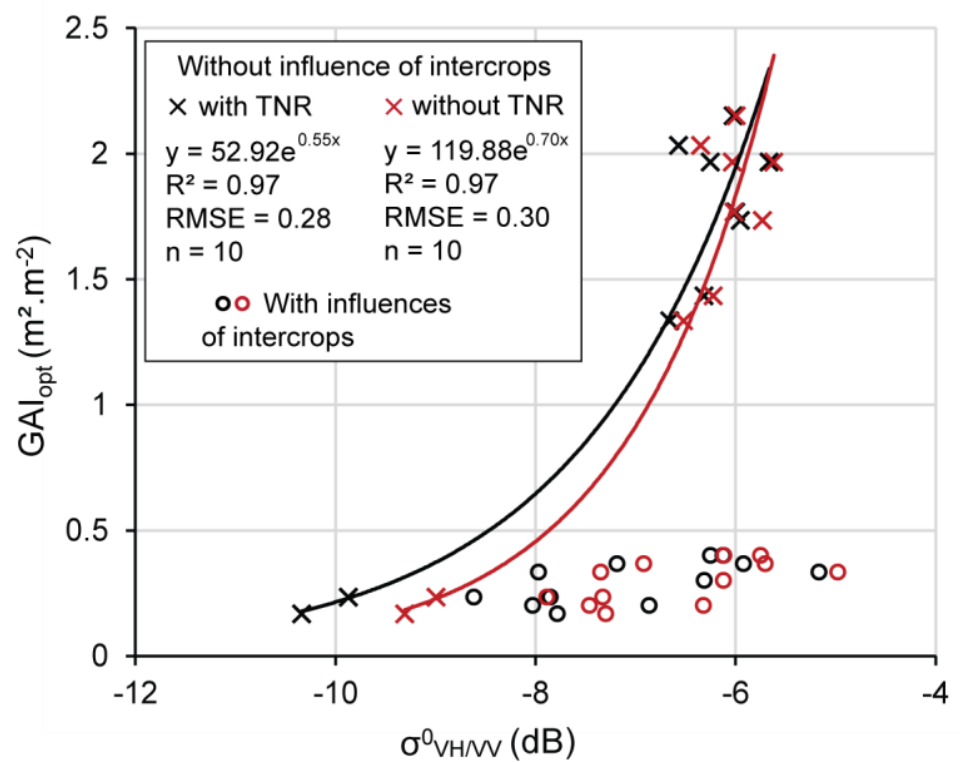

Figure 16. Impact of the presence of an intercrop on the empirical relationship estimated between $\sigma_{\mathrm{VH} / \mathrm{VV}}^{0}$ and the GAI of corn.

\section{Conclusions}

The aim of this work was to estimate the temporal evolution of popcorn dry masses (ear, plant, and total amount) at a field scale using an agro-meteorological model (SAFY-WB) controlled by GAI, derived from optical $\left(\mathrm{GAI}_{\mathrm{opt}}\right)$ and synthetic aperture radar (SAR) $\left(\mathrm{GAI}_{\mathrm{sar}}\right)$ satellite images and total dry masses (TDM) measured in-situ. 
The results show that once calibrated for one field, the total dry masses were accurately simulated with a daily time step in the range 0 to $20 t \cdot h a^{-1}\left(R^{2}=0.92\right.$; rRMSE $\left.=23 \%\right)$. The simulated TDM must be nevertheless corrected from the underestimation trend, by applying a scaling factor equal to 1.17 $\left(\mathrm{TDM}_{\mathrm{sim}}=0.85 . \mathrm{TDM}_{\text {meas }}+0.14\right)$ in order to obtain accurate absolute values. Moreover, the use of the model permitted separating the TDM into ear and plant dry masses (EDM and PDM) with good performances $\left(R^{2}>0.90\right)$. The approach also permitted accurate simulation (seven days of offset) of the following four phenological stages: four to five leaves, flowering, ripening, and harvest. The Discussion section pointed out some important points to consider for a good estimate of dry masses of corn during the preprocessing steps. In our study case, it was not wise to apply a speckle filter to the SAR data (because of the specific shape of some of the fields), whereas it was important to apply the thermal noise removal in order to obtain an accurate simulation of the dry masses.

From an agronomic point of view, the results have shown that new agricultural techniques (with intercrop management) significantly affects the SAR signal, which becomes unusable for establishing the relationship with GAI during the first phenological stages of the crop. This phenomenon was not observed when plots of corn were cultivated traditionally without intercrops.

This work could be extended to larger areas governed by heterogeneous climatic conditions. In this case, a dense network of weather stations is required to control the agro-meteorological model with local climatic measurements (wind, temperature, radiation, etc.). Moreover, the limitation in

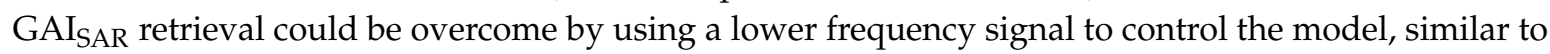
that offered by ALOS-2 PALSAR sensors (L-band).

Author Contributions: F.B.: writing_-original draft preparation, methodology, analysis and supervision; M.A.: software, validation and reference data; F.B. R.F., F.F. and S.C.: writing-review and editing; F.B. and J.-F.B.: funding acquisition.

Funding: This research is part of the PRECIEL project, funded by ACMG, Agralis, Nouvelle-Aquitaine Region, European Union, and CESBIO, and certified by Agri Sud-Ouest Innovation.

Acknowledgments: We are very grateful to the farmers involved (the Nataïs society, M. Labedan, the domain of Villeneuve, M. Darrieux), and to Sylvaine Laburthe for her valuable English proofreading.

Conflicts of Interest: The authors declare no conflict of interest.

\section{References}

1. Béziat, P.; Ceschia, E.; Dedieu, G. Carbon balance of a three crop succession over two cropland sites in South West France. Agric. For. Meteorol. 2009, 149, 1628-1645. [CrossRef]

2. Ceschia, E.; Beziat, P.; Dejoux, J.; Aubinet, M.; Bernhofer, C.; Bodson, B.; Buchmann, N.; Carrara, A.; Cellier, P.; Di Tommasi, P.; et al. Management effects on net ecosystem carbon and GHG budgets at European crop sites. Agric. Ecosyst. Environ. 2010, 139, 363-383. [CrossRef]

3. Hansen, E.; Djurhuus, J. Nitrate leaching as influenced by soil tillage and catch crop. Soil Tillage Res. 1997, 41, 203-219. [CrossRef]

4. Ward, P.; Flower, K.; Cordingley, N.; Weeks, C.; Micin, S. Soil water balance with cover crops and conservation agriculture in a Mediterranean climate. Field Crop. Res. 2012, 132, 33-39. [CrossRef]

5. Bastiaanssen, W.G.; Molden, D.J.; Makin, I.W. Remote sensing for irrigated agriculture: Examples from research and possible applications. Agric. Water Manag. 2000, 46, 137-155. [CrossRef]

6. Kalluri, S.; Gilruth, P.; Bergman, R. The potential of remote sensing data for decision makers at the state, local and tribal level: Experiences from NASA's Synergy program. Environ. Sci. Policy 2003, 6, 487-500. [CrossRef]

7. Seelan, S.K.; Laguette, S.; Casady, G.M.; Seielstad, G.A. Remote sensing applications for precision agriculture: A learning community approach. Remote Sens. Environ. 2003, 88, 157-169. [CrossRef]

8. Drusch, M.; Del Bello, U.; Carlier, S.; Colin, O.; Fernandez, V.; Gascon, F.; Hoersch, B.; Isola, C.; Laberinti, P.; Martimort, P.; et al. Sentinel-2: ESA's Optical High-Resolution Mission for GMES Operational Services. Remote Sens. Environ. 2012, 120, 25-36. [CrossRef]

9. Roy, D.P.; Wulder, M.A.; Loveland, T.R.; Woodcock, C.E.; Allen, R.G.; Anderson, M.C.; Helder, D.; Irons, J.R.; Johnson, D.M.; Kennedy, R.; et al. Landsat-8: Science and product vision for terrestrial global change research. Remote Sens. Environ. 2014, 145, 154-172. [CrossRef] 
10. Torres, R.; Snoeij, P.; Geudtner, D.; Bibby, D.; Davidson, M.; Attema, E.; Potin, P.; Rommen, B.; Floury, N.; Brown, M.; et al. GMES Sentinel-1 mission. Remote Sens. Environ. 2012, 120, 9-24. [CrossRef]

11. Baghdadi, N.; Boyer, N.; Todoroff, P.; El Hajj, M.; Bégué, A. Potential of SAR sensors TerraSAR-X, ASAR/ENVISAT and PALSAR/ALOS for monitoring sugarcane crops on Reunion Island. Remote Sens. Environ. 2009, 113, 1724-1738. [CrossRef]

12. Fieuzal, R.; Baup, F.; Marais-Sicre, C. Monitoring Wheat and Rapeseed by Using Synchronous Optical and Radar Satellite Data-From Temporal Signatures to Crop Parameters Estimation. Adv. Remote Sens. 2013, 2, 162-180. [CrossRef]

13. Fieuzal, R.; Baup, F.; Marais-Sicre, C. Sensitivity of TERRASAR-X, RADARSAT-2 and ALOS Satellite Radar Data to Crop Variables. In Proceedings of the Geoscience and Remote Sensing Symposium (IGARSS), Munich, Germany, 22-27 July 2012; pp. 3740-3743.

14. McNairn, H.; Champagne, C.; Shang, J.; Holmstrom, D.; Reichert, G. Integration of optical and Synthetic Aperture Radar (SAR) imagery for delivering operational annual crop inventories. ISPRS J. Photogramm. Remote Sens. 2009, 64, 434-449. [CrossRef]

15. Betbeder, J.; Fieuzal, R.; Philippets, Y.; Ferro-Famil, L.; Baup, F. Contribution of multitemporal polarimetric synthetic aperture radar data for monitoring winter wheat and rapeseed crops. J. Appl. Remote Sens. 2016, 10, 026020. [CrossRef]

16. Betbeder, J.; Fieuzal, R.; Baup, F. Assimilation of LAI and Dry Biomass Data from Optical and SAR Images into an Agro-Meteorological Model to Estimate Soybean Yield. IEEE J. Sel. Top. Appl. Earth Obs. Remote Sens. 2016, 9, 2540-2553. [CrossRef]

17. Zribi, M.; Le Hégarat-Mascle, S.; Ottlé, C.; Kammoun, B.; Guerin, C. Surface soil moisture estimation from the synergistic use of the (multi-incidence and multi-resolution) active microwave ERS Wind Scatterometer and SAR data. Remote Sens. Environ. 2003, 86, 30-41. [CrossRef]

18. Battude, M.; Al Bitar, A.; Brut, A.; Tallec, T.; Huc, M.; Cros, J.; Weber, J.-J.; Lhuissier, L.; Simonneaux, V.; Demarez, V. Modeling water needs and total irrigation depths of maize crop in the south west of France using high spatial and temporal resolution satellite imagery. Agric. Water Manag. 2017, 189, 123-136. [CrossRef]

19. Fieuzal, R.; Duchemin, B.; Jarlan, L.; Zribi, M.; Baup, F.; Merlin, O.; Hagolle, O.; Garatuza-Payan, J. Combined use of optical and radar satellite data for the monitoring of irrigation and soil moisture of wheat crops. Hydrol. Earth Syst. Sci. 2011, 15, 1117-1129. [CrossRef]

20. Sicre, C.M.; Baup, F.; Fieuzal, R. Determination of the crop row orientations from Formosat-2 multi-temporal and panchromatic images. ISPRS J. Photogramm. Remote Sens. 2014, 94, 127-142. [CrossRef]

21. Yang, H.; Chen, E.; Li, Z.; Zhao, C.; Yang, G.; Pignatti, S.; Casa, R.; Zhao, L. Wheat lodging monitoring using polarimetric index from RADARSAT-2 data. Int. J. Appl. Earth Obs. Geoinf. 2015, 34, 157-166. [CrossRef]

22. Haboudane, D. Hyperspectral vegetation indices and novel algorithms for predicting green LAI of crop canopies: Modeling and validation in the context of precision agriculture. Remote Sens. Environ. 2004, 90, 337-352. [CrossRef]

23. Claverie, M.; Demarez, V.; Duchemin, B.; Hagolle, O.; Ducrot, D.; Marais-Sicre, C.; Dejoux, J.-F.; Huc, M.; Keravec, P.; Béziat, P.; et al. Maize and sunflower biomass estimation in southwest France using high spatial and temporal resolution remote sensing data. Remote Sens. Environ. 2012, 124, 844-857. [CrossRef]

24. Fang, H.; Liang, S.; Hoogenboom, G.; Teasdale, J.; Cavigelli, M. Corn-yield estimation through assimilation of remotely sensed data into the CSM-CERES-Maize model. Int. J. Remote Sens. 2008, 29, 3011-3032. [CrossRef]

25. Liu, J.; Pattey, E.; Miller, J.R.; McNairn, H.; Smith, A.; Hu, B. Estimating crop stresses, aboveground dry biomass and yield of corn using multi-temporal optical data combined with a radiation use efficiency model. Remote Sens. Environ. 2010, 114, 1167-1177. [CrossRef]

26. Lobell, D.B.; Asner, G.P.; Ortiz-Monasterio, J.; Benning, T.L. Remote sensing of regional crop production in the Yaqui Valley, Mexico: Estimates and uncertainties. Agric. Ecosyst. Environ. 2003, 94, 205-220. [CrossRef]

27. Moulin, S.; Bondeau, A.; Delécolle, R. Combining agricultural crop models and satellite observations: From field to regional scales. Int. J. Remote Sens. 1998, 19, 1021-1036. [CrossRef]

28. Maas, S.J. GRAMI: A Crop Growth Model that Can Use Remotely Sensed Information; ARS-U.S. Department of Agriculture, Agricultural Research Service: Weslaco, TX, USA, 1992; Volume 91, 78p.

29. Hsiao, T.C.; Heng, L.; Steduto, P.; Rojas-Lara, B.; Raes, D.; Fereres, E. AquaCrop-The FAO Crop Model to Simulate Yield Response to Water: III. Parameterization and Testing for Maize. Agron. J. 2009, 101, 448-459. [CrossRef] 
30. Duchemin, B.; Fieuzal, R.; Rivera, M.A.; Ezzahar, J.; Jarlan, L.; Rodriguez, J.C.; Hagolle, O.; Watts, C. Impact of Sowing Date on Yield and Water Use Efficiency of Wheat Analyzed through Spatial Modeling and FORMOSAT-2 Images. Remote Sens. 2015, 7, 5951-5979. [CrossRef]

31. Duchemin, B.; Maisongrande, P.; Boulet, G.; Benhadj, I. A simple algorithm for yield estimates: Evaluation for semi-arid irrigated winter wheat monitored with green leaf area index. Environ. Model. Softw. 2008, 23, 876-892. [CrossRef]

32. Dente, L.; Satalino, G.; Mattia, F.; Rinaldi, M. Assimilation of leaf area index derived from ASAR and MERIS data into CERES-Wheat model to map wheat yield. Remote Sens. Environ. 2008, 112, 1395-1407. [CrossRef]

33. Fieuzal, R.; Baup, F.; Sicre, C.M. Estimation of corn yield using multi-temporal optical and radar satellite data and artificial neural networks. Int. J. Appl. Earth Obs. Geoinf. 2017, 57, 14-23. [CrossRef]

34. Baup, F.; Villa, L.; Fieuzal, R.; Ameline, M. Sensitivity of X-Band $(\sigma 0, \gamma)$ and Optical (NDVI) Satellite Data to Corn Biophysical Parameters. Adv. Remote Sens. 2016, 5, 103-117. [CrossRef]

35. Ameline, M.; Fieuzal, R.; Betbeder, J.; Berthoumieu, J.F.; Baup, F. Estimation of Corn Yield by Assimilating SAR and Optical Time Series into a Simplified Agro-Meteorological Model: From Diagnostic to Forecast. IEEE J. Sel. Top. Appl. Earth Obs. Remote Sens. 2018, 11, 4747-4760. [CrossRef]

36. Rinaldi, M.; Satalino, G.; Mattia, F.; Balenzano, A.; Perego, A.; Acutis, M.; Ruggieri, S. Assimilation of COSMO-SkyMed-derived LAI maps into the AQUATER crop growth simulation model. Capitanata (Southern Italy) case study. Eur. J. Remote Sens. 2013, 46, 891-908. [CrossRef]

37. Veloso, A.; Mermoz, S.; Bouvet, A.; Le Toan, T.; Planells, M.; Dejoux, J.-F.; Ceschia, E. Understanding the temporal behavior of crops using Sentinel-1 and Sentinel-2-like data for agricultural applications. Remote Sens. Environ. 2017, 199, 415-426. [CrossRef]

38. Monteith, J.L.; Moss, C.J.; Cooke, G.W.; Pirie, N.W.; Bell, G.D.H. Climate and the efficiency of crop production in Britain. Philos. Trans. R. Soc. Lond. B Biol. Sci. 1977, 281, 277-294. [CrossRef]

39. Maas, S.J. Parameterized Model of Gramineous Crop Growth: I. Leaf Area and Dry Mass Simulation. Agron. J. 1993, 85, 348-353. [CrossRef]

40. Sánchez, B.; Rasmussen, A.; Porter, J.R. Temperatures and the growth and development of maize and rice: A review. Glob. Chang. Biol. 2014, 20, 408-417. [CrossRef] [PubMed]

41. Battude, M.; Al Bitar, A.; Morin, D.; Cros, J.; Huc, M.; Sicre, C.M.; Le Dantec, V.; Demarez, V. Estimating maize biomass and yield over large areas using high spatial and temporal resolution Sentinel-2 like remote sensing data. Remote Sens. Environ. 2016, 184, 668-681. [CrossRef]

42. Fieuzal, R.; Sicre, C.M.; Baup, F. Estimation of Sunflower Yield Using a Simplified Agrometeorological Model Controlled by Optical and SAR Satellite Data. IEEE J. Sel. Top. Appl. Earth Obs. Remote Sens. 2017, 10, 5412-5422. [CrossRef]

43. Baret, F.; Hagolle, O.; Geiger, B.; Bicheron, P.; Miras, B.; Huc, M.; Berthelot, B.; Niño, F.; Weiss, M.; Samain, O.; et al. LAI, fAPAR and fCover CYCLOPES global products derived from VEGETATION. Remote Sens. Environ. 2007, 110, 275-286. [CrossRef]

44. Oh, Y. Quantitative retrieval of soil moisture content and surface roughness from multipolarized radar observations of bare soil surfaces. IEEE Trans. Geosci. Remote Sens. 2004, 42, 596-601. [CrossRef]

45. Gao, S.; Niu, Z.; Huang, N.; Hou, X. Estimating the Leaf Area Index, height and biomass of maize using HJ-1 and RADARSAT-2. Int. J. Appl. Earth Obs. Geoinf. 2013, 24, 1-8. [CrossRef]

46. Macelloni, G.; Paloscia, S.; Pampaloni, P.; Marliani, F.; Gai, M. The relationship between the backscattering coefficient and the biomass of narrow and broad leaf crops. IEEE Trans. Geosci. Remote Sens. 2001, 39, 873-884. [CrossRef]

47. Pinter, P.J., Jr.; Hatfield, J.L.; Schepers, J.S.; Barnes, E.M.; Moran, M.S.; Daughtry, C.S.T.; Upchurch, D.R. Remote Sensing for Crop Management. Photogramm. Eng. Remote Sens. 2003, 69, 647-664. [CrossRef]

48. Ban, Y. Orbital effects on ERS-1 SAR temporal backscatter profiles of agricultural crops. Int. J. Remote Sens. 1998, 19, 3465-3470. [CrossRef]

49. Joseph, A.T.; van der Velde, R.; O'Neill, P.E.; Lang, R.; Gish, T. Effects of corn on C- and L-band radar backscatter: A correction method for soil moisture retrieval. Remote Sens. Environ. 2010, 114, 2417-2430. [CrossRef]

50. O'Keeffe, K. Maize Growth \& Development; State of New South Wales through NSW Department of Primary Industries; NSW Department of Primary Industries: Orange, Australia, 2009; ISBN 978-0-7347-1955-3. 
51. Çakir, R. Effect of water stress at different development stages on vegetative and reproductive growth of corn. Field Crop. Res. 2004, 89, 1-16. [CrossRef]

52. Denmead, O.T.; Shaw, R.H. The Effects of Soil Moisture Stress at Different Stages of Growth on the Development and Yield of Corn1. Agron. J. 1960, 52, 272-274. [CrossRef]

53. Vollrath, A.; Lindquist, E.; Jonckheere, I.; Pekkarinen, A. Open Foris SAR Toolkit-Free and Open Source Command Line Utilities for Automatized SAR Data Pre-Processing. In Proceedings of the Living Planet Symposium 2016, Prague, Czech Republic, 9-13 May 2016; Volume 740, p. 31, ISBN 978-92-9221-305-3.

54. Gorelick, N.; Hancher, M.; Dixon, M.; Ilyushchenko, S.; Thau, D.; Moore, R. Google Earth Engine: Planetary-scale geospatial analysis for everyone. Remote Sens. Environ. 2017, 202, 18-27. [CrossRef]

55. Miranda, N.; Hajduch, G. Masking "No-Value" Pixels on GRD Products Generated by the Sentinel-1 ESA IPF. Issue 2.1, Reference MPC-0243. 2018, p. 14. Available online: https://sentinel.esa.int/documents/247904/ 2142675/Sentinel-1-masking-no-value-pixels-grd-products-note (accessed on 21 August 2019).

56. Miranda, N.; Meadows, P.J. Radiometric Calibration of S-1 Level-1 Products Generated by the S-1 IPF. Technical Note; Reference ESA-EOPG-CSCOP-TN-0002, Issue 1. 2015. Available online: https://sentinel.esa.int/ documents/247904/685163/S1-Radiometric-Calibration-V1.0.pdf (accessed on 21 August 2019).

57. Lee, J.S. Refined filtering of image noise using local statistics. Comput. Graph. Image Process. 1981, 15, 380-389. [CrossRef]

(C) 2019 by the authors. Licensee MDPI, Basel, Switzerland. This article is an open access article distributed under the terms and conditions of the Creative Commons Attribution (CC BY) license (http://creativecommons.org/licenses/by/4.0/). 